\title{
The effect of the frequencies of three consecutive content words on eye movements during reading
}

\author{
Timothy J. Slattery, Alexander Pollatsek, and Keith Rayner \\ University of Massachusetts, Amherst, Massachusetts
}

\begin{abstract}
The frequencies of three consecutive content words were simultaneously varied in the first sentence of a two-sentence passage. Various eye movement measures of first-pass processing (first-fixation duration, gaze duration, and go-past time) all revealed frequency effects for all three words. The size of the effect did not differ significantly across the three words on either first-fixation duration or gaze duration, but it increased markedly for go-past time from the first to the second word, possibly indicating an accumulation of the difficulty of processing. In addition, there was a delayed effect of the frequency manipulation: For the sentences with three low-frequency words, processing at the beginning of the next (second) sentence was lengthened. (The beginning of the second sentence was always at least four words from the last of the frequency-manipulated words.) These findings indicate that word frequency has effects beyond initial lexical access in reading. A list of the experimental items and supplemental analyses may be downloaded from www.psychonomic.org/archive.
\end{abstract}

Researchers who investigate eye movements during reading have known for 2 decades that the amount of time a person spends fixating a word is inversely related to the word's frequency (Rayner, 1998). There have been numerous experiments conducted to investigate the word frequency effect in reading. Some of these examined the fixation times of all the words in a passage of text and then used regression techniques to estimate how much of the differences in the fixation times could be explained by word frequency, as opposed to other factors, such as word length (Just \& Carpenter, 1980; Kliegl, Nuthmann, \& Engbert, 2006). In other studies, however, the effect of word frequency has been investigated more directly by manipulating the frequency of a single target word within a sentence (Inhoff \& Rayner, 1986; Juhasz, Liversedge, White, \& Rayner, 2006; Rayner \& Duffy, 1986) while controlling word length (and other potentially confounding variables). For example, in Juhasz et al., readers were given one of the two sentences below in a counterbalanced design, and the basic finding was that fixation time on the (italicized) low-frequency (LF) target word was longer than fixation time on the high-frequency (HF) target word:

1. We were unable to repair the damaged ligament even though we tried. (LF)

2. We were unable to repair the damaged marriage even though we tried. (HF)

In recent years, there has been a growing debate over whether or not words are lexically processed serially or in parallel during eye fixations while reading (see Reichle, Rayner, \& Pollatsek, 2003). However, despite all the investigations of word frequency in reading, and despite the fact that current models of reading rely heavily on word frequency, as well as assumptions of serial or parallel word processing (Engbert, Longtin, \& Kliegl, 2002; Engbert, Nuthmann, Richter, \& Kliegl, 2005; Pollatsek, Reichle, \& Rayner, 2006; Reichle, Pollatsek, Fisher, \& Rayner, 1998; Reichle et al., 2003; Reilly \& Radach, 2003, 2006; Richter, Engbert, \& Kliegl, 2006), there have been surprisingly few studies in which the effects of consecutive LF versus HF words have been investigated to determine whether the effect of the whole is greater than the sum of the effects of its parts. In fact, in only one study has the frequency of multiple words within a sentence frame been manipulated (Rayner, Sereno, Morris, Schmauder, \& Clifton, 1989). Rayner et al. (1989) were interested in how text integration and word frequency would jointly affect fixation durations on words. To do this, they examined readers' eye movements while they read sentences that contained either a single noun whose frequency was manipulated or an adjective-noun pair in which the frequency of both was manipulated (the adjective and the noun were both either LF or HF). The following are examples of the stimuli used by Rayner et al. (1989); the words in italics represent the target, frequency-manipulated words:

3. The tiger started to growl. (LF)

4. The fierce tiger started to growl. (LF-LF)

5. A theory will explain the facts. (HF)

\section{A simple theory will explain the facts. (HF-HF)}

The two main findings of this study were that LF words (both adjectives and nouns) were fixated longer than HF words and nouns were fixated for a longer time when they

T. J. Slattery, tslatter@psych.umass.edu 
were modified by an adjective than when they were presented in isolation. However, the frequency of the adjective had no effect on the gaze duration (the sum of all of the fixations on the word before moving to another word) on the noun: The difference in gaze duration between HF and LF nouns was just as large when the nouns appeared without modifiers as when the nouns were modified by an HF or LF adjective.

It would seem from this study that there is no cumulative effect of word frequency. However, Rayner et al. (1989) did not examine the region following the initial noun to check whether the frequency of the adjective had an effect on the word that followed the target noun. Such effects in eye movements have been shown before and have come to be termed spillover or lag effects (Kliegl et al., 2006; Rayner \& Duffy, 1986; Schroyens, Vitu, Brysbaert, \& d'Ydewalle, 1999). In addition, the E-Z Reader (Pollatsek et al., 2006), SWIFT (Engbert et al., 2005), and Glenmore (Reilly \& Radach, 2006) models of eye movements during reading all predict spillover or lag effects. In fact, it has recently been argued by Kliegl et al. that lag effects of word frequency on single-fixation durations are larger than the effect of the frequency of the currently fixated word. It is possible, then, that in Rayner et al. (1989), there was a cumulative effect of word frequency but that it appeared only in spillover onto the next word.

The purpose of the present study was to investigate what the effects of manipulating the frequency of consecutive content words in a sentence are, both on the frequencymanipulated words themselves and further "downstream" in the text. Moreover, to make an even stronger manipulation than that in Rayner et al.'s (1989) study, we manipulated the frequency of three consecutive target words: The three words were either all HF or all LF. Each stimulus consisted of two sentences, with the word frequency manipulation occurring in the first sentence. The second sentence was included as a continuation, so that reading would proceed normally beyond the end of the first sentence and also so that potential delayed frequency effects could be observed, especially at the sentential boundary. Such effects might plausibly surface because there are well-documented sentence wrap-up effects in reading (Hirotani, Frazier, \& Rayner, 2006; Rayner, Kambe, \& Duffy, 2000; Rayner et al., 1989). These have usually been demonstrated in the context of semantic/syntactic manipulations and suggest that although much processing is done online (Rayner et al., 2000), some of the processing is delayed until the end of the sentence. It seems reasonable that in the present study, there could be analogous wrap-up effects that reflected an effort to fully understand the meaning of a sentence before the reader went on to the next sentence. Whether the time course of such an effect would be exactly the same as that for the wrap-up effects cited above, however, was an open question.

\section{METHOD}

\section{Participants}

Thirty-four members of the University of Massachusetts community participated in the experiment. They had either normal vision or vision corrected to normal with contact lenses. All were native speakers of American English and were naive as to the purpose of the experiment. They either were provided with extra credit for psychology classes or were paid $\$ 8$ for their participation.

\section{Apparatus}

A Fourward Technologies Dual Purkinje Eyetracker (Generation VI) was used to record the readers' eye movements. Eye movements were recorded from the right eye, but viewing was binocular. The participants were seated $61 \mathrm{~cm}$ from the computer screen, and 3.8 characters equaled $1^{\circ}$ of visual angle. Head movements were minimized by use of a bite bar and headrests.

\section{Materials}

There were 24 pairs of sentences. Each pair consisted of an LF and an HF version, which differed only in the three critical frequency words, as shown in Examples 7 and 8 below. ${ }^{1}$ (The frequencies of the Francis \& Kučera, 1982, corpus were used.) The following are the LF and the HF versions (respectively) of the stimuli used in the experiment:

7. The rival warriors ambushed the vulnerable guard patrol. During the battle, the commander fled out of fear. (LF)

8. The enemy soldiers attacked the vulnerable guard patrol. During the battle, the commander fled out of fear. (HF)

For purposes of analysis, the first sentence of each pair was broken into three regions. The first, the frequency region, consisted of the three frequency-manipulated words (rival, warriors, and ambushed in Sentence 7). The rest of the first sentence was broken into two regions, a sentence continuation region (the vulnerable guard) and the final word region (patrol). The sentence continuation region consisted of three or four words following the frequency region (mean length $=21.25$ characters, $S D=3.41$ characters). The final word region consisted of the last word of the first sentence and the space before it (mean length $=7.79$ characters, $S D=1.70$ characters). As can be seen in the example above, the only difference between the LF and the HF versions of the stimuli was the three words in the frequency region. It is also important to note that the entire first sentence and the beginning of the second sentence of each stimulus were presented to the participants on a single line of text. This was done to prevent return sweeps (large eye movements that bring the eye to the beginning of the next line) from making it difficult to interpret processing times at the end of the first sentence.

In most word frequency studies, there has been a single cutoff point for classifying a word as HF or LF, and although the cutoff point has varied, many studies have classified words with frequencies of 100 or more (per million) as HF and words with frequencies of 10 or less as LF. In the present study, the criterion for distinguishing between HF and LF words could not be as straightforward, because each pair of words not only was (approximately) controlled for length, but also had similar meanings. We felt that a very important control was to keep the meaning of the HF and the LF target words as similar as possible, so that any effects on eye movements that appeared after the spillover region would be easier to interpret. Given that constraint, we could not equate the difference in frequency between the HF and the LF words at the three target positions. However, there was a large difference in average frequency between the LF and the HF words (11.45 and 162.48 occurrences per million words, respectively). Moreover, for each pair of HF and the LF target words at each of the positions, the mean difference in log frequency was about the same (see Table 1).

\section{Procedure}

On their arrival for the experiment, a bite bar was prepared for the participants. Next, they were familiarized with the eyetracker and given detailed verbal instructions on the experimental procedures. Then the eyetracker was calibrated for the participants. The accuracy of the calibration was checked after each trial. The participants read 
Table 1

Characteristics of the Three Target Words

\begin{tabular}{|c|c|c|c|c|c|c|c|c|c|}
\hline \multirow[b]{3}{*}{ Position } & \multirow[b]{3}{*}{ Frequency } & \multicolumn{4}{|c|}{ All Items } & \multicolumn{4}{|c|}{ Without Predictable Words } \\
\hline & & \multicolumn{2}{|c|}{$\begin{array}{l}\text { Length in } \\
\text { Characters }\end{array}$} & \multicolumn{2}{|c|}{$\begin{array}{l}\log _{10} \\
\text { Frequency }\end{array}$} & \multicolumn{2}{|c|}{$\begin{array}{l}\text { Length in } \\
\text { Characters }\end{array}$} & \multicolumn{2}{|c|}{$\begin{array}{c}\log _{10} \\
\text { Frequency }\end{array}$} \\
\hline & & $M$ & $S D$ & $M$ & $S D$ & $M$ & $S D$ & $M$ & $S D$ \\
\hline First word & & $\begin{array}{l}6.2 \\
6.4\end{array}$ & $\begin{array}{l}1.6 \\
1.5\end{array}$ & & $\begin{array}{l}1.3 \\
0.8\end{array}$ & $\begin{array}{l}6.1 \\
6.3\end{array}$ & $\begin{array}{l}1.3 \\
1.3\end{array}$ & $\begin{array}{l}2.1 \\
5.1\end{array}$ & $\begin{array}{l}1.3 \\
0.6\end{array}$ \\
\hline Second word & $\begin{array}{l}\text { Low } \\
\text { High }\end{array}$ & $\begin{array}{l}6.6 \\
6.2\end{array}$ & $\begin{array}{l}1.3 \\
1.6\end{array}$ & $\begin{array}{l}0.91 \\
2.07\end{array}$ & $\begin{array}{l}1.1 \\
0.7\end{array}$ & $\begin{array}{l}6.9 \\
6.8\end{array}$ & $\begin{array}{l}1.3 \\
1.3\end{array}$ & $\begin{array}{l}2.0 \\
4.6\end{array}$ & $\begin{array}{l}1.1 \\
0.6\end{array}$ \\
\hline Th & $\begin{array}{l}\text { Low } \\
\text { High }\end{array}$ & $\begin{array}{l}5.5 \\
5.9 \\
\end{array}$ & $\begin{array}{l}1.6 \\
1.5 \\
\end{array}$ & $\begin{array}{l}0.85 \\
2.11 \\
\end{array}$ & $\begin{array}{l}1.3 \\
0.7 \\
\end{array}$ & $\begin{array}{l}6.1 \\
6.1 \\
\end{array}$ & $\begin{array}{l}1.6 \\
1.7 \\
\end{array}$ & $\begin{array}{l}2.3 \\
4.9 \\
\end{array}$ & $\begin{array}{l}1.0 \\
0.8 \\
\end{array}$ \\
\hline
\end{tabular}

Note-The frequencies of the Francis and Kučera (1982) corpus were used.

the sentences at their own rate and signaled that they had finished reading a sentence by pressing a button. Multiple-choice questions with two alternative answers were given after each trial in order to check for comprehension. The participants answered with a buttonpress. They were correct over $90 \%$ of the time, indicating that they were reading for comprehension. The first five trials were practice trials to get the participants comfortable with the task. Experimental items were presented in one of two counterbalancing conditions in a random order, along with 108 filler items. The filler items consisted of two sentence stimuli that were presented as two lines of text so that they would have a visually similar text layout as the experimental items. Comprehension questions, similar to the ones given after the experimental questions, were given after a third of the filler items.

\section{Post Hoc Predictability Assessment}

Another variable that has been shown to effect the fixation times on words during reading is word predictability (Drieghe, Rayner, \& Pollatsek, 2005; Ehrlich \& Rayner, 1981; Rayner \&Well, 1996), and predictability of the target words was assessed post hoc to eliminate effects due to a few highly predictable words. Word predictability was assessed by using a CLOZE task in which a separate set of participants was asked to guess the next word in the sentence, given all the words up to that word. Fourteen participants from the same population as that used in the online reading experiment judged the predictability of the words in the experimental items. In the complete set of 24 items, the average predictability in the LF condition was 0 for the first and second word positions and .043 for the third word position. For the HF condition, the average predictability was .006 for the first word position, .026 for the second word position, and .110 for the third word position. However, 8 of the 24 item pairs contained a frequency-manipulated target word with a predictability value above $15 \%$. Although $15 \%$ predictability on a CLOZE task might not be considered very large, a separate analysis was performed in which these item pairs were removed from the data in order to ensure that effects were not due to this confounding. When the items that had a highly predictable word were removed, the average predictability for the first and second word positions was 0 in both conditions, and the predictability of the third word position was .009 in both conditions.

\section{RESULTS}

The experiment was a two-factor (word position and frequency) within-participants design. Trials were removed from the data analysis when blinks or track losses occurred on the first line of text (blinks and track losses after the return sweep to the second line did not cause the trial to be removed from the analysis) or when the first stable fixation was on the first frequency-manipulated target word. In all, 74 of 816 , or $9.1 \%$, of the trials were removed for these reasons. In addition, fixations shorter than $80 \mathrm{msec}$ or longer than $1,000 \mathrm{msec}$ were removed from the data set. In order to remove variance due to counterbalancing, counterbalancing condition was included as a between-subjects/items factor in all of the analyses that follow (Pollatsek \& Well, 1995).

\section{Frequency-Manipulated Words (The Frequency Region)}

Table 2 presents the various measures of reading in this region, with the data for the analysis without predictable target words appearing in parentheses.

First, consider the first-fixation duration, or the duration of the first fixation on a target word, conditional on the word's being fixated at least once on the first pass through the text. (Fixations were counted as being on the target word if they were on the target word or the space before it.) There were clear word frequency effects on first-fixation duration for each of the three target words in the frequency region. First-fixation durations were 20, 28, and $35 \mathrm{msec}$ longer for the LF word than for the HF word for the first $\left[F_{1}(1,32)=\right.$ $\left.24.21, p<.001 ; F_{2}(1,22)=16.25, p<.01\right]$, second $\left[F_{1}(1,32)=14.43, p<.01 ; F_{2}(1,22)=8.46, p<.01\right]$, and third $\left[F_{1}(1,32)=18.30, p<.001 ; F_{2}(1,22)=22.34\right.$, $p<.001]$ positions. Although the frequency effect on firstfixation duration increased in an approximately linear fashion over the successive words, neither the frequency $\times$ word position interaction $\left[F_{1}(2,64)=1.66, p<.20 ; F_{2}<1\right]$ nor the linear trend of the difference between the LF and the HF versions over the successive words $\left[F_{1}(1,32)=2.65\right.$, $\left.p<.20 ; F_{2}(1,22)=1.90, p<.20\right]$ was significant. The quadratic trend of the difference between the LF and the HF versions over the successive words was also nonsignificant $(F \mathrm{~S}<1)$. In the analysis that excluded items with predictable target words, first-fixation durations were 20,32, and $28 \mathrm{msec}$ longer for the LF word than for the HF word for the first $\left[F_{1}(1,32)=3.20, p<.10 ; F_{2}(1,22)=2.45, p<\right.$ $.20]$, second $\left[F_{1}(1,32)=17.32, p<.001 ; F_{2}(1,22)=4.26\right.$, $p<.10]$, and third $\left[F_{1}(1,32)=7.67, p<.01 ; F_{2}(1,22)=\right.$ $11.97, p<.01]$ positions. As with the main analysis, there was no frequency $\times$ word position interaction $(F \mathrm{~s}<1)$. In addition, the linear and quadratic trends of the difference between the LF and the HF versions over the successive words did not approach significance $(F \mathrm{~s}<1)$. 
Table 2

Eye Movement Data for the Three Target Words in the Frequency Region

\begin{tabular}{|c|c|c|c|c|c|c|c|}
\hline Position & Frequency & $\begin{array}{c}\text { First } \\
\text { Fixation } \\
\text { Duration } \\
(\mathrm{msec})\end{array}$ & $\begin{array}{c}\text { Gaze } \\
\text { Duration } \\
(\mathrm{msec})\end{array}$ & $\begin{array}{c}\text { Probability } \\
\text { of First Pass } \\
\text { Fixation }\end{array}$ & $\begin{array}{c}\text { Probability } \\
\text { of Refixation }\end{array}$ & $\begin{array}{c}\text { Go-Past } \\
\text { Time } \\
(\mathrm{msec})\end{array}$ & $\begin{array}{c}\text { Probability of } \\
\text { a Regression }\end{array}$ \\
\hline \multirow[t]{2}{*}{ First word } & Low & $\begin{array}{c}247 \\
(214)\end{array}$ & $\begin{array}{c}302 \\
(259)\end{array}$ & $\begin{array}{c}.88 \\
(.88)\end{array}$ & $\begin{array}{l}.20 \\
(.17)\end{array}$ & $\begin{array}{c}319 \\
(267)\end{array}$ & $\begin{array}{c}.04 \\
(.02)\end{array}$ \\
\hline & High & $\begin{array}{c}227 \\
(194)\end{array}$ & $\begin{array}{c}247 \\
(209)\end{array}$ & $\begin{array}{c}.87 \\
(.86)\end{array}$ & $\begin{array}{c}.11 \\
(.09)\end{array}$ & $\begin{array}{c}271 \\
(224)\end{array}$ & $\begin{array}{c}.06 \\
(.04)\end{array}$ \\
\hline Difference & & $\begin{array}{c}20 \\
(20)\end{array}$ & $\begin{array}{c}55 \\
(50)\end{array}$ & $\begin{array}{c}.01 \\
(.02)\end{array}$ & $\begin{array}{l}.09 \\
(.08)\end{array}$ & $\begin{array}{c}48 \\
(43)\end{array}$ & $\begin{array}{l}-.02 \\
(-.02)\end{array}$ \\
\hline \multirow[t]{2}{*}{ Second word } & Low & $\begin{array}{c}286 \\
(274)\end{array}$ & $\begin{array}{c}324 \\
(308)\end{array}$ & $\begin{array}{c}.91 \\
(.94)\end{array}$ & $\begin{array}{c}.25 \\
(.28)\end{array}$ & $\begin{array}{c}427 \\
(406)\end{array}$ & $\begin{array}{l}.16 \\
(.15)\end{array}$ \\
\hline & High & $\begin{array}{c}258 \\
(242)\end{array}$ & $\begin{array}{c}278 \\
(259)\end{array}$ & $\begin{array}{l}.85 \\
(.90)\end{array}$ & $\begin{array}{c}.12 \\
(.11)\end{array}$ & $\begin{array}{c}327 \\
(288)\end{array}$ & $\begin{array}{c}.12 \\
(.09)\end{array}$ \\
\hline Difference & & $\begin{array}{c}28 \\
(32)\end{array}$ & $\begin{array}{c}46 \\
(49)\end{array}$ & $\begin{array}{c}.06 \\
(.04)\end{array}$ & $\begin{array}{l}.13 \\
(.17)\end{array}$ & $\begin{array}{c}100 \\
(118)\end{array}$ & $\begin{array}{c}.04 \\
(.06)\end{array}$ \\
\hline \multirow[t]{2}{*}{ Third word } & Low & $\begin{array}{c}280 \\
(240)\end{array}$ & $\begin{array}{c}313 \\
(272)\end{array}$ & $\begin{array}{l}.85 \\
(.88)\end{array}$ & $\begin{array}{l}.18 \\
(.19)\end{array}$ & $\begin{array}{c}399 \\
(325)\end{array}$ & $\begin{array}{c}.14 \\
(.10)\end{array}$ \\
\hline & High & $\begin{array}{c}245 \\
(212)\end{array}$ & $\begin{array}{c}273 \\
(237)\end{array}$ & $\begin{array}{c}.83 \\
(.85)\end{array}$ & $\begin{array}{l}.14 \\
(.16)\end{array}$ & $\begin{array}{c}318 \\
(277)\end{array}$ & $\begin{array}{l}.10 \\
(.09)\end{array}$ \\
\hline Difference & & $\begin{array}{c}35 \\
(28) \\
\end{array}$ & $\begin{array}{c}41 \\
(35)\end{array}$ & $\begin{array}{c}.02 \\
(.03)\end{array}$ & $\begin{array}{c}.04 \\
(.03)\end{array}$ & $\begin{array}{c}81 \\
(48) \\
\end{array}$ & $\begin{array}{c}.04 \\
(.01)\end{array}$ \\
\hline
\end{tabular}

Note-Means without predictable items are given in parentheses.

A measure of somewhat later processing is the gaze $d u$ ration, the sum of the fixation durations on a target word, conditional on the word's being fixated at least once on the first pass through the text. Again, there were clear frequency effects on gaze duration for each of the three positions in the frequency region (see Table 2). Gaze durations were 55, 46, and $40 \mathrm{msec}$ longer for the LF word than for the HF word for the first $\left[F_{1}(1,32)=31.39, p<\right.$ $\left..001 ; F_{2}(1,22)=32.25, p<.001\right]$, second $\left[F_{1}(1,32)=\right.$ $\left.26.89, p<.001 ; F_{2}(1,22)=21.75, p<.001\right]$, and third $\left[F_{1}(1,32)=17.55, p<.001 ; F_{2}(1,22)=20.80, p<.001\right]$ positions. Note that the size of the frequency effect actually decreased from the first to the third word, the opposite trend of what was observed for first-fixation duration. However, as with the first fixation duration data, neither the frequency $\times$ word position interaction nor the linear or quadratic trends of the difference between the LF and the HF versions over the successive words was significant $(F \mathrm{~s}<1)$. In the analysis without predictable target words, gaze durations were 50,49, and $35 \mathrm{msec}$ longer for the LF word than for the HF word for the first $\left[F_{1}(1,32)=10.70\right.$, $\left.p<.01 ; F_{2}(1,22)=12.98, p<.01\right]$, second $\left[F_{1}(1,32)=\right.$ $\left.17.89, p<.001 ; F_{2}(1,22)=8.73, p<.05\right]$, and third $\left[F_{1}(1,32)=8.94, p<.01 ; F_{2}(1,22)=8.02, p<.05\right]$ positions. As with the main analysis, neither the frequency $x$ word position interaction nor the linear or quadratic trends in the difference between the LF and the HF versions over the successive words was significant (all $F_{\mathrm{s}}<1$ ).

Another early measure of processing is the probability of fixating a target word. There was little difference in the probability of making a first-pass fixation on the target word over the successive words (averaging over frequency): Word $1=.87$, Word $2=.88$, and Word $3=.84\left[F_{1}(2,64)=\right.$ $\left.2.12, p<.20 ; F_{2}(2,46)=1.12, p>.20\right]$. On average, the LF target words were fixated .03 more often than the HF words $\left[F_{1}(1,32)=5.59, p<.05 ; F_{2}(1,22)=5.33, p<\right.$
$.05]$. However, the frequency difference for Positions 1 and 3 was not significant $\left(F_{\mathrm{S}}<1\right)$, and even the .06 difference for the second word was not significant in the item analysis $\left[F_{1}(1,32)=5.59, p<.05 ; F_{2}(1,22)=2.59, p<.20\right]$. In addition, the linear and quadratic trends of the frequency $x$ word position interaction were all nonsignificant $(p \mathrm{~s}>$ .20). The data with the predictable target words removed were similar to the data in the main analysis with a few minor differences. First, there was a main effect of word position in the participant analysis, with the second word having been fixated more often: Word $1=.87$, Word $2=.92$, and Word $3=.87\left[F_{1}(2,64)=4.41, p<.05 ; F_{2}(2,28)=\right.$ $3.11, p<.10]$. Second, the main effect of frequency, averaging over the three word positions, was no longer significant $\left[F_{1}(1,32)=3.16, p<.10 ; F_{2}(1,22)=4.45, p<\right.$ $.10]$. As with the earlier analysis, the frequency difference for Positions 1 and 3 was not significant $\left(F_{\mathbf{S}}<1\right)$, and the .04 difference for the second word also was not significant $\left[F_{1}(1,32)=2.15, p<.20 ; F_{2}(1,22)=3.52, p<.10\right]$. Again, the linear and quadratic trends of the frequency $X$ word position interaction were nonsignificant (all $F_{\mathrm{S}}<1$ ).

As was noted above, the trends over serial position for the frequency effects in first-fixation duration and gaze duration were in opposite directions, with first-fixation durations increasing over the three positions and gaze durations decreasing. One possible cause for this difference is that the probability of refixating may show an increasing frequency effect over the three positions. Averaging over word position, there was a main effect of frequency $\left[F_{1}(1,32)=45.24, p<.001 ; F_{2}(1,22)=18.18, p<\right.$ $.001]$. However, there was no main effect for word position $\left[F_{1}(2,64)=1.20, p>.30 ; F_{2}<1\right]$, and the interaction of frequency and word position approached but did not reach significance $\left[F_{1}(2,64)=3.10, p<.10 ; F_{2}(1,22)=\right.$ $2.75, p<.10]$. The differences in the probability of refixation due to frequency were $.09, .13$, and .04 for the three 
positions, respectively $\left[F_{1}(1,32)=8.29, p<.01\right.$, and $F_{2}(1,22)=11.19, p<.01 ; F_{1}(1,32)=38.46, p<.001$, and $F_{2}(1,22)=12.89, p<.01 ; F_{1}(1,32)=2.16, p<.20$, and $\left.F_{2}(1,22)=1.82, p<.20\right]$. Although there was no linear trend in the word position $\times$ frequency data $(F \mathrm{~s}<1)$, the quadratic trend was significant in the participants analysis $\left[F_{1}(1,32)=7.81, p<.01 ; F_{2}(1,22)=3.34, p<\right.$ $.10]$. The analysis without predictable target words was similar but had a stronger quadratic trend. The differences in the probability of refixation due to frequency were $6 \%$, $17 \%$, and $3 \%$ for the three positions $\left[F_{1}(1,32)=6.10, p<\right.$ .05 , and $F_{2}(1,22)=11.33, p<.01 ; F_{1}(1,32)=18.12$, $p<.001$, and $F_{2}(1,22)=13.33, p<.01 ; F_{1}<1$, and $\left.F_{2}(1,22)=1.18, p>.20\right]$. There was a significant frequency $\times$ word position interaction $\left[F_{1}(2,64)=4.04, p<\right.$ $\left..05 ; F_{2}(2,28)=4.54, p<.05\right]$, and the quadratic trend in the data was also significant $\left[F_{1}(1,32)=5.75, p<.05\right.$; $\left.F_{2}(1,14)=6.71, p<.05\right]$, but the linear trend was not $\left[F_{1}(1,32)=1.24, p>.20 ; F_{2}(1,14)=1.09, p>.20\right]$.

Since the effects in the probability of refixation data are quite equivocal, it is likely that a significant contributor to the difference in trend between the gaze duration data and the first-fixation data was the duration of the second fixation on a word, and in an analysis of the items, that appeared to be the case: The effects of frequency on the second-fixation durations for the three word positions were 39,17 , and $15 \mathrm{msec}$, respectively. However, due to the low probability of a refixation (about $16 \%$ overall), there was little power in the analyses (especially the participant analysis), and the effect was not significant at any of the three word positions even in the items analysis [first word, $F_{2}(1,13)=2.89, p<.20$; second and third words, $F \mathrm{~s}<1]$.

It thus appears from the gaze duration measure that there is no cumulating effect of the frequency manipulation; if anything, there is a slight suggestion of the opposite. However, the gaze duration measure assesses only the time spent on a word before the eyes move off of it and does not assess whether there were regressions back from the word or more time spent on that word (following a regression) before the reader moved on to the next word in the text. A measure that includes both gaze duration and all the cost of regressing back from it is go-past time: the sum of all fixations from when a word or region is first fixated until it is crossed to the right (until it is "gone past"); this includes fixations on earlier words in the sentence (Liversedge, Paterson, \& Pickering, 1998, Rayner \& Duffy, 1986). There were main effects of frequency $\left[F_{1}(1,32)=\right.$ 59.64, $\left.p<.001 ; F_{2}(1,22)=20.84, p<.001\right]$ and word position $\left[F_{1}(2,64)=20.13, p<.001 ; F_{2}(2,44)=13.96\right.$, $p<.001]$, but no interaction $\left[F_{1}(2,64)=2.59, p<.10\right.$; $\left.F_{2}(2,44)=1.92, p<.20\right]$. The linear and quadratic trends in the difference between the LF and the HF versions over the successive words were not significant $\left[F_{1}(1,32)=\right.$ $2.25, p<.20$, and $F_{2}(1,22)=1.26, p>.20 ; F_{1}(1,32)=$ $2.93, p<.10$, and $F_{2}(1,22)=2.84, p<.20$, respectively]. The go-past times were longer for LF words at all three word positions (see Table 2) [first, $F_{1}(1,32)=13.67, p<$ .01 , and $F_{2}(1,22)=14.25, p<.01$; second, $F_{1}(1,32)=$ $35.09, p<.001$, and $F_{2}(1,22)=19.01, p<.001$; third,
$F_{1}(1,32)=16.98, p<.001$, and $F_{2}(1,22)=7.51, p<$ $.05]$. The difference in go-past reading times between the LF and the HF versions of the sentences was larger for the second word position than for the first word position $\left[F_{1}(1,32)=5.81, p<.05 ; F_{2}(1,22)=5.94, p<\right.$ $.05]$ but was not larger for the third word position than for the first $\left[F_{1}(1,32)=2.25, p<.20 ; F_{2}(1,22)=1.26, p>\right.$ $.20]$. There was clearly little difference in the effect of frequency on go-past reading times between the second and the third word positions $\left(F_{\mathbf{S}}<1\right)$. In the analysis without predictable target words, there were still main effects of frequency $\left[F_{1}(1,32)=34.55, p<.001 ; F_{2}(1,14)=11.80\right.$, $p<.01]$ and word position $\left[F_{1}(2,64)=25.71, p<.001\right.$; $\left.F_{2}(2,28)=17.28, p<.001\right]$, and there was also a significant interaction $\left[F_{1}(2,64)=4.34, p<.05 ; F_{2}(2,28)=\right.$ $4.25, p<.05]$. The linear trend in the difference between the LF and the HF versions over the successive words was not significant $\left(F_{\mathrm{s}}<1\right)$, but the quadratic trend was $\left[F_{1}(1,32)=5.75, p<.05 ; F_{2}(1,22)=7.50, p<.05\right]$. Go-past times were longer for LF words in all three word positions [first, $F_{1}(1,32)=6.23, p<.05$, and $F_{2}(1,14)=$ $7.60, p<.05$; second, $F_{1}(1,32)=19.78, p<.001$, and $F_{2}(1,14)=11.76, p<.01$; third (significant by participants only), $F_{1}(1,32)=10.80, p<.01$, and $F_{2}(1,14)=$ $2.65, p<.20]$. Again, the difference between the LF and the HF versions of the sentences was larger for the second word position than for the first $\left[F_{1}(1,32)=4.52, p<.05\right.$; $\left.F_{2}(1,14)=6.02, p<.05\right]$, but in this analysis, it was also larger than that for the third word position $\left[F_{1}(1,32)=\right.$ $\left.6.25, p<.05 ; F_{2}(1,14)=5.93, p<.05\right]$. In this subset of the data, there was clearly no difference in the effect of frequency on go-past reading times between the first and the third word positions $\left(F_{\mathrm{S}}<1\right)$.

In sum, it appears that the question of whether there were cumulative effects of frequency over the three target word locations depends on the measure used. There is a suggestion of a cumulative frequency effect when the first-fixation durations are examined, a suggestion of an opposite effect when the gaze duration is examined, and a clearer indication of a cumulative frequency effect (at least between Locations 1 and 2) when an even later measure, the go-past time, is used. We will discuss these data later.

\section{Effects of Frequency After Leaving the Frequency Region}

The prior analysis of the frequency region was word by word. The following analyses of the downstream effects of the frequencies of the three target words are more global: region by region (see Table 3 ). In this section, all the analyses reported are on the complete set of 24 items. Perhaps a good baseline against which to view the downstream effects of frequency is to consider the frequency effect for the frequency region as a whole. (Note that the first-pass reading time measure, the gaze duration on the region, is not necessarily the sum of the data presented earlier for the individual frequency-manipulated words, since, for example, individual words are skipped.) For the combined frequency region, the word frequency effects were $177 \mathrm{msec}$ on first-pass reading time $\left[F_{1}(1,33)=74.26\right.$, $\left.p<.001 ; F_{2}(1,23)=42.7, p<.001\right], 0.54$ on the number 
Table 3

Eye Movement Data for the Sentence Regions

\begin{tabular}{lcccc}
\hline \multicolumn{1}{c}{ Region } & Frequency & $\begin{array}{c}\text { First Pass } \\
(\mathrm{msec})\end{array}$ & $\begin{array}{c}\text { Number of } \\
\text { Fixations }\end{array}$ & $\begin{array}{c}\text { Percentage of } \\
\text { Regressions Out }\end{array}$ \\
\hline Frequency & Low & 932 & 3.68 & 5.5 \\
\multirow{5}{*}{ Sentence continuation } & High & 754 & 3.14 & 5.3 \\
& Low & 423 & 1.77 & 9.7 \\
\multirow{2}{*}{ Final word } & High & 399 & 1.68 & 5.5 \\
\multirow{3}{*}{ Begin } & Low & 504 & 1.90 & 13.6 \\
& High & 509 & 1.94 & 14.9 \\
& Low & 324 & 1.18 & 3.6 \\
\hline
\end{tabular}

of fixations in the region on first pass $\left[F_{1}(1,33)=32.57\right.$, $\left.p<.001 ; F_{2}(1,23)=28.87, p<.001\right]$, but only $0.2 \%$ on regressions out of the region $(F \mathrm{~s}<1)$. (However, since the frequency region was near the beginning of the sentence, there was not much to regress to from this region.)

Previous studies have shown that effects of word frequency can "spill over" onto the next fixation (Rayner \& Duffy, 1986). The sentence continuation region was defined to capture such spillover effects. Note that the sentence continuation region and all subsequent regions consisted of the same words for both the LF and the HF versions of the sentences, so that any effect in those regions had to come from what was read before. There were small frequency effects on the sentence continuation region for first-pass reading time [ $23 \mathrm{msec} ; F_{1}(1,33)=2.97, p<$ $\left..10 ; F_{2}(1,23)=3.01, p<.10\right]$ and for the number of firstpass fixations $\left[.09 ; F_{1}(1,33)=2.46, p<.20 ; F_{2}(1,23)=\right.$ $4.37, p<.05]$. In contrast, the number of regressions from the sentence continuation region in the LF condition was about double that in the HF condition (see Table 3); however, the difference was only marginally significant by items $\left[F_{1}(1,33)=4.77, p<.05 ; F_{2}(1,23)=3.30, p<\right.$ $.10]$. In addition, when we examined the duration of the first fixation on the sentence continuation region (which could be anywhere in the sentence continuation region), there was virtually no frequency effect $(1 \mathrm{msec}$ in the "wrong direction"; $t \mathrm{~s}<1$ ).

The final word region consisted of the last word in the first sentence. Rayner et al. (2000; Rayner et al., 1989) found that a word was fixated longer if it ended a sentence than if it was sentence internal. It has been hypothesized that this effect is due to recoding that occurs at the end of the sentence. Thus, there was reason to suspect that there might be frequency effects here if there was some final recomputation of the meaning of the sentence before the reader moved on to the next sentence. However, there were virtually no effects of the frequency manipulation on this word (see Table 3). The mean first-pass reading time was actually $4 \mathrm{msec}$ longer for the HF versions of the stimuli $\left(F_{\mathrm{S}}<1\right)$, the number of fixations was .04 greater for the $\mathrm{HF}$ versions of the stimuli $\left(F_{\mathbf{S}}<1\right)$, and there were also actually $1.4 \%$ more regressions for the HF versions of the stimuli $\left(F_{\mathbf{S}}<1\right)$.

In contrast to the result above, the frequency of the words at the beginning of the first sentence appeared to affect processing at the beginning of the second sentence. The frequency effect on first-pass reading times on the first word of the second sentence $(18 \mathrm{msec})$ was significant by participants $\left[F_{1}(1,33)=4.38, p<.05 ; F_{2}(1,23)=\right.$ $2.85, p>.10]$, and the frequency effect on the number of fixations in the region (.09) was significant, by both participants and items $\left[F_{1}(1,33)=8.66, p<.01 ; F_{2}(1,23)=\right.$ $7.50, p<.025]$. There were also about $0.5 \%$ more regressions from this region for the LF sentences, but the effect was not close to significant $(F \mathbf{s}<1)$.

\section{DISCUSSION}

In the present study, a novel manipulation of word frequency was used to investigate lexical access and the extent to which "unfinished business" from a word influences processing of the next word or has effects laterplausibly, at or near the end of the sentence. In the study, we manipulated the frequency of three consecutive content words while controlling for word meaning and length. In fact, the frequency manipulation produced large and significant differences in fixation time on all three words, a marginal effect in the spillover region, and a significant difference in processing time at the beginning of the second sentence. We think that the pattern of frequency effects, particularly those in the frequency region and at the beginning of the second sentence, have implications for the process of reading.

First, let's consider the pattern of results in the frequency region. Intuitively, one might expect something like a cumulative effect of the frequency difference as a reader progresses through the frequency region. For example, if one assumes only partial processing of a word before the reader goes on to the next word, one might expect that frequency effects would "pile up" going through the region. In particular, the E-Z Reader model (Pollatsek et al., 2006; Reichle et al., 1998; Reichle et al., 2003) assumes that a preliminary stage of word identification $\left(\mathrm{L}_{1}\right)$ is the signal to move the eyes to the next word, whereas a full stage of word identification $\left(\mathrm{L}_{2}\right)$ is the trigger to shift attention to the next word and to begin processing it. The time required for both stages, $\mathrm{L}_{1}$ and $\mathrm{L}_{2}$, are assumed to decrease with increasing frequency and increasing predictability of a word. When the reader shifts attention to word $n$, the word identification system begins $\mathrm{L}_{1}$. When $\mathrm{L}_{1}$ is completed, a signal is sent to the oculomotor system to move the eyes to word $n+1$, and $\mathrm{M}_{1}$ (the first, labile stage of eye movement programming) begins. Once $\mathrm{L}_{2}$ of the word identification system finishes, a signal is sent 
to the visual system to move attention to word $n+1$. This shift of attention to word $n+1$ causes the word identification system to begin $\mathrm{L}_{1}$ on word $n+1$. Meanwhile, back in the oculomotor system, the completion of $\mathrm{M}_{1}$ will cause the start of $\mathrm{M}_{2}$ (the second, nonlabile stage of eye movement programming), and at the end of this stage, a saccade will be executed. E-Z Reader accounts for skips largely by the speed of lexical processing of word $n+1$. That is, if $\mathrm{M}_{1}$ for the saccade from $n$ to $n+1$ is completed prior to the completion of $\mathrm{L}_{1}$ for word $n+1$, a saccade will be executed to word $n+1$, but if $\mathrm{L}_{1}$ for word $n+1$ finishes before $\mathrm{M}_{1}$ is completed, a new saccade program will be initiated to word $n+2$, and word $n+1$ will be skipped. (E-Z Reader also accounts for a small number of skips by errors in targeting saccades.)

The E-Z Reader model predicts that the difference in first-fixation durations and gaze durations between the LF and the HF words will be somewhat larger for the second and third words than for the first, because the second and third LF words would be processed more slowly than their HF counterparts, not only because of frequency differences between these words, but also because they would be processed less in the parafovea than their HF counterparts, due to increased $\mathrm{L}_{2}$ time on the prior word. (Increased $\mathrm{L}_{2}$ time causes spillover effects in the model.) However, E-Z Reader predicts that spillover effects end there, and there should be no effect of the frequency of the first word on the third. However, quantitatively, these spillover effects are predicted to be fairly modest; for example, for frequency differences such as those that occurred in this study, these spillover effects would be predicted to be on the order of $7 \mathrm{msec}$ for first-fixation durations. Thus, E-Z Reader would predict that the frequency effect on the first-fixation duration on Word 2 in the frequency region should be about $7 \mathrm{msec}$ more than that on Word 1, because it should reflect the "true" frequency effect plus the spillover from Word 1. As was indicated above, the effect predicted for Word 3 should be equal to that for Word 2, because the predicted effects of spillover last only for one word. In addition, the model would predict a spillover effect on first-fixation duration of about $7 \mathrm{msec}$ for the sentence continuation region, since only a spillover effect should be observed because the words in the region are identical in the HF and the LF versions.

The first-fixation data are not too far off from the predictions of the E-Z Reader model, since there are fixation duration differences of 20,28 , and $35 \mathrm{msec}$ for the three words in the frequency region (see Table 2). Since none of these differences are reliable, especially the difference between the latter two, the E-Z Reader model is fairly compatible with these data. However, it does appear that effects on the first-fixation duration are cumulating a bit more than predicted by E-Z Reader. E-Z Reader would also predict a small frequency effect on the first-fixation duration on the sentence continuation region (about $5-10 \mathrm{msec}$ ). It is not clear whether a failure to find an effect here is a serious problem for the model. The gaze duration data are a bit more problematic for E-Z Reader, however, since E-Z Reader would predict that the pattern of effects in gaze duration would be roughly the same as that for first-fixation durations (i.e., a greater frequency effect for Words 2 and 3 than for Word 1). However, as can be seen in Table 2, although the size of the frequency effect is much greater for gaze duration than for firstfixation duration, it actually decreases from Word 1 to Words 2 and 3. This is not compatible with the E-Z Reader model. The modest frequency effect on gaze duration in the sentence continuation region, however, seems compatible with the E-Z Reader model.

What really complicates the picture for the E-Z Reader model, however, is the pattern for go-past times (which includes regressions back to prior words before a word is exited to the right). Here, the frequency effect is about twice as big for both Word 2 and Word 3 as for Word 1 (see Table 2) in the analysis with all the items and about twice as big for Word 2 as for Words 1 and 3 for the analysis without predictable items. E-Z Reader posits that all interword regressions (such as those that contribute to go-past time) are due to factors beyond word encoding, except those that are due to errors of eye movement targeting. Because there would be no reason to predict any differences of targeting due to frequency differences, E-Z Reader would posit that these regressions are not due to increasing difficulties in encoding the words themselves but to "higher order" differences, such as failing to construct a meaning for the text read so far. (It should also be noted that these increased regressions may be an explanation of the gaze duration pattern; that is, a regression may cancel a second fixation on the word.) However, until E-Z Reader incorporates a model of sentence understanding, it has to rely largely on ad hoc assumptions about sentence difficulty to explain such relatively localized types of processing difficulty. ${ }^{2}$

Two alternative models of eye movement control in reading are the Glenmore model (Reilly \& Radach, 2006) and the SWIFT model (Engbert et al., 2002; Engbert et al., 2005; Richter et al., 2006). These models have a number of similarities: Both assume that lexical processing occurs for multiple words in parallel; both assume that the activation level of a word is a function of word frequency (as well as other factors); both assume that these word activations are used within the framework of a saliency map for saccade target selection; and both assume that the rate of processing a word decreases with increasing distance of the word from the current fixation point. However, there is one aspect in which the models differ that is highly relevant to the present study: The Glenmore model assumes competition for limited processing resources, which effectively limits the parallel processing in Glenmore much more than in SWIFT. As a result, we feel that Glenmore's predictions would be similar to the E-Z Reader predictions stated above. However, because Glenmore posits continuing lexical processing of word $n-1$ while word $n$ is fixated, it may be capable of predicting the regression pattern in the present study without recourse to positing difficulty in postlexical processing.

Before attempting to make predictions from SWIFT, we would like to point out what we believe is a serious problem with the model (although it is a problem with the model's implementation, and not with the underlying as- 
sumptions). In SWIFT, the predictability of word $n$ is used to modulate its activation before word $n-1$ (and in many cases, $n-2$ ) has been lexically accessed, which we feel is psychologically and mathematically implausible. Both SWIFT and E-Z Reader use word predictability, operationalized as the probability of guessing word $n$, given all the words in the sentence up through word $n-1$. This can be expressed mathematically as $P($ word $n \mid$ words $1,2 \ldots$ $n-1)$. In E-Z Reader, this seems reasonable, since processing of words is serial, so that all of these words are assumed to have been fully lexically accessed before attention shifts to word $n$. In contrast, in SWIFT, a word has not been lexically accessed until its activation has risen to its peak and then fallen back down to zero. This does not occur for word $n-1$ until quite a bit of processing of $n$ has occurred (in fact, it is often the case that word $n$ has been preprocessed by the model before $n-2$ has been lexically accessed). Thus, it is hard to see how the predictability of word $n$ can be computed, given that the prior words are, according to the model, often not fully accessed.

Due to the issue above, we will restrict our discussion of the SWIFT model to the analysis without the predictable target words. In this sample of the items, the predictability of the three target words was very low and was the same across the experimental conditions, so the argument above should have minimal impact on SWIFT's predictions. The model posits that words within the perceptual span (usually about three or four words) are processed in parallel, with processing being graded across the regionbeing highest for foveal vision. The model is quite complex, and it is difficult to ascertain what this model would predict for our set of data, because the fixation durations within the SWIFT framework are the results of the push and pull of attraction from words both to the right and to the left of fixation. Nonetheless, it is worth noting that Kliegl et al. (2006) recently claimed that their data indicated that the effect on the fixation time of the frequency of a word (word $n$ ) is larger on the subsequent word (word $n+1)$ than it is on word $n$ and concluded that these data are strong evidence in favor of a model such as SWIFT. ${ }^{3}$ If so, this would mean that the frequency effects on Words 2 and 3 should be at least double the size of the effects on Word 1 and that the frequency effect in the spillover region should be at least as large as that on the first frequencymanipulated word. These predictions would appear to be counter to what was observed in the present data, with the possible exception of the go-past data.

We also tried to work through the model to see whether some variant of it could predict the pattern of data we observed. Since the HF and the LF versions of the stimuli are identical up to the point of the frequency word region, the model would seem to predict similar fixation patterns up to the point where the first target word has had some parafoveal preprocessing. This occurred very quickly in the present study, since the first target word was often the second word of the sentence. Upon fixating the first target word, in the LF condition, the model predicts that this word will be fixated longer than its HF counterpart, due to foveal inhibition that begins after a 50-msec delay, thus predicting a frequency effect (of indeterminate size) on the first target word. Determining what the model would predict for the frequency effect on the second word without running simulations is a bit trickier. The amount of foveal inhibition that a fixation receives depends on the activation of the word in the fovea, which in turn depends on the amount of preprocessing the word has undergone. For example, it could be that the extra time spent on the first LF target word allows for enough preprocessing of the second word, relative to its HF counterpart, that the second target word actually has an attenuated frequency effect. But this will depend on the parameters that specify the rate of lexical activation, decay, and amount of foveal inhibition, among other things. Nonetheless, as was noted above, Kliegl et al. (2006) seem confident that the model predicts spillover effects due to word frequency that are larger than the effects on the target word.

One piece of data from the present study that we believe SWIFT might have a difficult time predicting is the large number of regressions from the second target word in the LF condition (indicated by the large frequency effect in go-past times on the second word). The reason this may be difficult is that at the second target word, there is still an LF word to the right of fixation that should be a strong competitor for the next fixation. The model would seem to predict that the largest number of regressions (and the largest difference between conditions) should occur at the third word position, where the word to the right of fixation is higher in frequency and is the same across experimental conditions.

As far as we can tell, the pattern of data we observed, especially that for go-past time, is not easily explained by current versions of either the SWIFT or the E-Z Reader model (we are less certain that Glenmore would have equal difficulty with the regression and go-past time results). What seems like an interesting question is whether either model can be adapted to predict these effects solely on the basis of word frequency's affecting the encoding of individual words or whether such effects would need to be explained by higher order difficulties in text processing that occur as the result of more than one LF word being encountered in a sequence. What may be more relevant is whether the LF words make it harder to quickly assess what the topic of the discourse is and, thus, interfere with processing the meaning of subsequent words. However, this would be difficult to distinguish from a model in which the difficulty in lexical access of a prior word is still having a large effect on the difficulty in lexical access of a subsequent word.

Now let us turn to the delayed effects of the frequency of the target words - specifically, the effect at the beginning of the second sentence. As we have indicated, this effect is much later than standard spillover effects that have often been observed. In addition, the effect is somewhat different in time course from an often observed sentence wrap-up effect: A word is fixated longer when it is sentence final then when it is sentence internal (Rayner et al. 2000, Rayner et al., 1989). This wrap-up effect is hypothesized to be due to the extra processing needed to be sure that a correct analysis of the sentence has been achieved. The processing generally envisaged in explaining this ef- 
fect is some sort of semantic/syntactic clean-up operation (although see Hirotani et al., 2006, for an alternative account). However, both the HF and the LF versions of these two-sentence passages had not only the same firstsentence final words, but also the same syntax. Although we are not certain why the effect we observed appears at the beginning of the second sentence, rather than at the end of the first sentence, one possibility is that semantic/ syntactic clean-up at the end of the first sentence is completed more quickly than the integration of the meaning of the lexical items. Thus, the effect we observed may be part of a sentence wrap-up process, but just delayed a fixation or so because it is dealing with ensuring that details of the meaning of the first sentence have been understood, rather than just ensuring that the sentence has been parsed correctly.

In summary, our data indicate that the frequency of a word has at least three effects in reading. First, consistent with many prior experiments, we found that the frequency of a word significantly affected the duration of fixations on that word. In addition, we found that the frequency of prior words in a three-word sequence affected go-past times on later words in the sequence. This could reflect either continuing lexical processing of the target word or postlexical processing difficulty. This effect was largely due to regressions back to the prior word. Finally, as was just discussed, we observed that the frequency of three words that occurred early in a sentence had significant effects on the first word of the following sentence, likely reflecting some sort of difficulty in meaning integration of the LF version of the first sentence that spills over into the second sentence.

\section{AUTHOR NOTE}

This article is based on the first author's Master's thesis at the University of Massachusetts, and portions of the data were presented at the European Conference on Eye Movements, Dundee, 2004. The research was supported by Grant HD26765 from the National Institutes of Health. We thank Reinhold Kliegl and two anonymous reviewers for their helpful comments on an earlier version of the manuscript. Correspondence should be addressed to T. J. Slattery, Department of Psychology, University of Massachusetts, Tobin Hall, Amherst, MA 01003 (e-mail: tslatter@ psych.umass.edu).

\section{REFERENCES}

Drieghe, D., Rayner, K., \& Pollatsek, A. (2005). Eye movements and word skipping during reading revisited. Journal of Experimental Psychology: Human Perception \& Performance, 31, 954-959.

EhrLich, S. F., \& RAYNer, K. (1981). Contextual effects on word perception and eye movements during reading. Journal of Verbal Learning \& Verbal Behavior, 20, 641-655.

Engbert, R., Longtin, A., \& Kliegl, R. (2002). A dynamical model of saccade generation in reading based on spatially distributed lexical processing. Vision Research, 42, 621-636.

Engbert, R., Nuthmann, A., Richter, E. M., \& Kliegl, R. (2005). SWIFT: A dynamical model of saccade generation during reading. Psychological Review, 112, 777-813

Francis, W. N., \& KuČERA, H. (1982). Frequency analysis of English usage: Lexicon and grammar. Boston: Houghton Mifflin.

Hirotani, M., Frazier, L., \& Rayner, K. (2006). Punctuation and intonation effects on clause and sentence wrap-up: Evidence from eye movements. Journal of Memory \& Language, 54, 425-443.

INHOFF, A. W., \& RAYNER, K. (1986). Parafoveal word processing dur- ing eye fixations in reading: Effects of word frequency. Perception \& Psychophysics, 40, 431-439.

Juhasz, B. J., Liversedge, S. P., White, S. J., \& Rayner, K. (2006). Binocular coordination of the eyes during reading: Word frequency and case alternation affect fixation duration but not fixation disparity. Quarterly Journal of Experimental Psychology, 59, 1614-1625.

Just, M. A., \& CARPENTER, P. A. (1980). A theory of reading: From eye fixations to comprehension. Psychological Review, 87, 329-354.

Kliegl, R., Nuthmann, A., \& Engbert, R. (2006). Tracking the mind during reading: The influence of past, present, and future words on fixation durations. Journal of Experimental Psychology: General, 135, 12-35.

Liversedge, S. P., Paterson, K. B., \& Pickering, M. (1998). Eye movements and measures of reading time. In G. Underwood (Ed.), Eye guidance in reading and scene perception (pp. 55-75). Oxford: Elsevier.

Pollatsek, A., Reichle, E. D., \& Rayner, K. (2006). Tests of the E-Z Reader model: Exploring the interface between cognition and eyemovement control. Cognitive Psychology, 52, 1-56.

Pollatsek, A., \& Well, A. D. (1995). On the use of counterbalanced designs in cognitive research: A suggestion for a better and more powerful analysis. Journal of Experimental Psychology: Learning, Memory, \& Cognition, 21, 785-794.

RAYNER, K. (1998). Eye movements in reading and information processing: 20 years of research. Psychological Bulletin, 124, 372-422.

RAYNER, K., \& DufFY, S. A. (1986). Lexical complexity and fixation times in reading: Effects of word frequency, verb complexity, and lexical ambiguity. Memory \& Cognition, 14, 191-201.

Rayner, K., Kambe, G., \& Duffy, S. A. (2000). The effect of clause wrap-up on eye movements during reading. Quarterly Journal of Experimental Psychology, 53A, 1061-1080.

Rayner, K., Pollatsek, A., Drieghe, D., Slattery, T. J., \& Reichle, E. D. (2007). Tracking the mind during reading via eye movements: Comments on Kliegl, Nuthmann, and Engbert (2006). Journal of Experimental Psychology: General, 136, 520-529.

Rayner, K., Sereno, S., Morris, R., Schmauder, A., \& Clifton, C., JR. (1989). Eye movements and online language comprehension processes. Language \& Cognitive Processes, 4, 21-49.

RAYNER, K., \& WELL, A. D. (1996). Effects of contextual constraint on eye movements in reading: A further examination. Psychonomic Bulletin \& Review, 3, 504-509.

Reichle, E. D., Pollatsek, A., Fisher, D. L., \& Rayner, K. (1998). Toward a model of eye movement control in reading. Psychological Review, 105, 125-157.

Reichle, E. D., Rayner, K., \& Pollatsek, A. (2003). The E-Z Reader model of eye-movement control in reading: Comparisons to other models. Behavioral \& Brain Sciences, 26, 445-526.

ReILly, R., \& RADACH, R. (2003). Foundations of an interactive activation model of eye movement control in reading. In J. Hyönä, R. Radach, \& H. Deubel (Eds.), The mind's eye: Cognitive and applied aspects of eye movement research (pp. 429-456). Amsterdam: Elsevier.

REILly, R., \& RADACH, R. (2006). Some empirical tests of an interactive activation model of eye movement control in reading. Cognitive Systems Research, 7, 34-55.

Richter, E. M., Engbert, R., \& Kliegl, R. (2006). Current advances in SWIFT. Cognitive Systems Research, 7, 23-33.

Schroyens, W., Vitu, F., Brysbaert, M., \& d'Ydewalle, G. (1999). Eye movement control during reading: Foveal load and parafoveal processing. Quarterly Journal of Experimental Psychology, 52A, 1021-1046.

\section{NOTES}

1. For a majority of the items ( 14 in the main analysis, 9 in the predictability-controlled analysis), the three frequency-manipulated words were consecutive, but the remaining items contained "the" between the second and the third word positions. A separate set of analyses comparing these items with those without intervening words showed that the results were quite similar for the two groups of items. We conducted an additional analysis that included this function word with the target frequency word that came before it. Also, the type of words in the frequencymanipulated region differed for the 24 experimental items. Eight of the items consisted of subject, verb, object constructions. Another 8 were 
adjective, noun, verb constructions (Items 9-16). And the final 8 items were either adjective, adjective, noun constructions or adjective, complex noun constructions (Items 17-24). An additional items analysis comparing these three groups showed that the groups did not significantly differ with respect to the trends in the frequency-manipulated region. These supplemental analyses, along with a list of the experimental items, can be found in the Psychonomic Society's Archive.

2. One mechanism we are currently exploring is that if there is a delay in the second stage of processing $\left(\mathrm{L}_{2}\right)$, which represents understanding the meaning of the word, a signal is sent to the eye movement system to program a fixation to the attended word (i.e., the word that is the source of the processing difficulty). If this signal arrives too late to countermand the signal to move on to the next word, it will result in a regression back to the word at which the processing difficulty is occurring.

3. However, we disagree with Kliegl et al.'s (2006) claims regarding the size of the frequency effect on the fixation time on a frequencymanipulated word and the size of the effect on the following word (see Rayner, Pollatsek, Drieghe, Slattery, \& Reichle, 2007).

\section{ARCHIVED MATERIALS}

The following materials associated with this article may be accessed through the Psychonomic Society's Norms, Stimuli, and Data archive, www.psychonomic.org/archive. To access these files, search the archive for this article using the journal name (Memory \& Cognition), the first author's name (Slattery), and the publication year (2007).

FILE: C203-slattery-Memory \& Cognition-2007.zip

DESCRIPTION: The compressed archive file contains two files:

List of experimental stimuli.doc

Supplemental analyses.doc

AUTHOR’s E-MAIL ADDRESs: tslatter@psych.umass.edu

(Manuscript received February 22, 2005; revision accepted for publication June 28, 2006.) 